Pacific Journal of Mathematic 


\title{
SPECTRAL ANALYSIS OF COLLECTIVELY COMPACT, STRONGLY CONVERGENT OPERATOR SEQUENCES
}

\author{
P. M. Anselone and T. W. Palmer
}

\begin{abstract}
A set of linear operators on a normed linear space is collectively compact if and only if the union of the images of the unit ball has compact closure. Bounded linear operators $T$ and $T_{n}, n=1,2, \cdots$, such that $T_{n} \rightarrow T$ strongly and $\left\{T_{n}-T\right\}$ is collectively compact are investigated. The theory somewhat resembles that for $\left\|T_{n}-T\right\| \rightarrow 0$. The spectrum of $T_{n}$ is eventually contained in any neighborhood of the spectrum of $T$. If $f(T)$ is defined by the operational calculus, then $f\left(T_{n}\right)$ is eventually defined, $f\left(T_{n}\right) \rightarrow f(T)$ strongly, and $\left\{f\left(T_{n}\right)-f(T)\right\}$ is collectively compact. If $f\left(T_{n}\right)$ and $f(T)$ are spectral projections, the corresponding spectral subspaces eventully have the same dimension. Other results compare eigenvalues and generalized eigenmanifolds of $T_{n}$ and $T$.
\end{abstract}

Let $X$ be a real or complex Banach space, $[X]$ the space of bounded linear operators on $X$ into $X$, and $\mathscr{B}$ the closed unit ball in $X$. Then a set $\mathscr{K} \subset[X]$ is collectively compact if and only if the set $\mathscr{K} \mathscr{B}=\{K x: K \in \mathscr{K}, x \in \mathscr{B}\}$ has compact closure. Collectively compact sets of operators were introduced in [1] in connection with the approximate solution of integral equations. Various general properties of such sets are developed in [2], which contains further references on the subject.

With slight modification, most of the preliminary results below are valid for operators from one space to another. By rather different methods, Atkinson [3] obtained some of the spectral theory results for the special case with $\left\{T_{n}\right\}$ collectively compact.

For the sake of brevity, strong operator convergence is denoted simply by $T_{n} \rightarrow T$ and norm convergence by $\left\|T_{n}-T\right\| \rightarrow 0$.

2. Related hypotheses. As indicated above, we shall study operators in $[X]$ such that $T_{n} \rightarrow T$ and $\left\{T_{n}-T\right\}$ is collectively compact. But, first, comparisons are made with related conditions. The hypotheses in (a) below were assumed in most of the previous papers on collectively compact sets.

Proposition 2.1. The following are equivalent.

(a) $T_{n} \rightarrow T$ and $\left\{T_{n}\right\}$ collectively compact;

(b) $T_{n} \rightarrow T,\left\{T_{n}-T\right\}$ collectively compact, $T$ compact;

(c) $T_{n} \rightarrow T,\left\{T_{n}-T\right\}$ collectively compact, some $T_{n}$ compact.

The proof makes use of the fact that the strong closure of a 
collectively compact set is collectively compact [2, Prop. 2.1].

Any totally bounded set of compact operators in $[X]$ is collectively compact, but not conversely [2, Th. 2.5 and Ex. 2.6]. The next proposition indicates the effect of relacing the hypothesis, $\left\{T_{n}-T\right\}$ collectively compact, by the hypothesis, $\left\{T_{n}-T\right\}$ totally bounded (or equivalently $\left\{T_{n}\right\}$ totally bounded).

Proposition 2.2. Let $T, T_{n} \in[X], n \geqq 1$. Then:

(a) $\left\|T_{n}-T\right\| \rightarrow 0$ if and only if $T_{n} \rightarrow T$ and $\left\{T_{n}-T\right\}$ totally bounded;

(b) $\left\|T_{n}-T\right\| \rightarrow 0$ and each $T_{n}-T$ compact $\Rightarrow\left\{T_{n}-T\right\}$ collectively compact.

Proof. (a) Clearly, $\left\|T_{n}-T\right\| \rightarrow 0$ implies $T_{n} \rightarrow T$ and $\left\{T_{n}-T\right\}$ totally bounded. If $\left\|T_{n}-T\right\| \nrightarrow 0$, then $\left\|T_{n_{i}}-T\right\|>\delta$ for some $\left\{n_{i}\right\}$ and $\delta>0$. But $T_{n} \rightarrow T$ and $\left\{T_{n}-T\right\}$ totally bounded imply $\left\|T_{n_{i_{j}}}-T\right\| \rightarrow 0$ for some $\left\{n_{i_{j}}\right\}$. This is a contradiction. (b) This follows from the fact that a totally bounded set of compact operators is collectively compact.

If $\left\|T_{n}-T\right\| \rightarrow 0$, then there is a simpler theory than that presented below. However, $\left\|T_{n}-T\right\| \not 0$ in a number of applications to integral equations.

Whenever $T_{n} \rightarrow T$, the principle of uniform boundedness implies that $\left\{T_{n}\right\}$ is bounded or, equivalently, equicontinuous. If follows that strong convergence is uniform on each compact subset of $X$. In contrast, $\left\|T_{n}-T\right\| \rightarrow 0$ if and only if $T_{n} \rightarrow T$ uniformly on each bounded subset of $X$, or simply on $\mathscr{B}$.

3. General convergence results. The following proposition will play an important role in our analysis.

Proposition 3.1. Assume $T_{n} \rightarrow T$ and $\mathscr{K} \subset[X]$ collectively compact. Then

$$
\left\|\left(T_{n}-T\right) K\right\| \rightarrow 0 \text { uniformly for } K \in \mathscr{K} .
$$

Proof. Since $\overline{\mathscr{K} \mathscr{B}}$ is compact, $\left(T_{n}-T\right) K x \rightarrow 0$ uniformly for $K \in \mathscr{K}$ and $X \in \mathscr{B}$.

The following convention will be used in the next proposition as well as later in the paper. Suppose $T_{\alpha n}, T_{\alpha} \in[X]$ for $n \geqq 1$ and $\alpha$ in an index set $A$. Then the phrase, $T_{\alpha n} \rightarrow T_{\alpha}$ uniformly for $\alpha \in A$, will mean that, for each $x \in X, T_{\alpha n} x \rightarrow T_{\alpha} x$ uniformly for $\alpha \in A$. In the following proposition $\mathscr{K}$ need not consist of compact operators.

Proposition 3.2. Assume $T_{n} \rightarrow T$ and $\mathscr{K} \subset[X]$ totally bounded. 
Then

$$
T_{n} K \rightarrow T K \text { uniformly for } K \in \mathscr{K} \text {. }
$$

Proof. Fix $x \in X$ and define the map $f: \overline{\mathscr{K}} \rightarrow X$ by $f(K)=K x$. Since $\overline{\mathscr{K}}$ is compact and $f$ is continuous, the set $f(\mathscr{\mathscr { K }})=\overline{\mathscr{K}} x$ is compact. The assertion follows.

The next result is essentially a corollary of Proposition 3.1.

Proposition 3.3. Assume $T_{n} \rightarrow T$ and $\left\{T_{n}-T\right\}$ collectively compact. Then $\left\|\left(T_{n}-T\right)^{2}\right\| \rightarrow 0$.

Although by itself the condition $\left\|\left(T_{n}-T\right)^{2}\right\| \rightarrow 0$ does not have very many useful consequences, it becomes more important when the operators have appropriate additional properties.

Theorem 3.4. Let $X$ be a Hilbert space. Assume $T_{n} \rightarrow T$ and $\left\{T_{n}-T\right\}$ collectively compact. Then $\left\|T_{n}-T\right\| \rightarrow 0$ :

(a) if each $T_{n}$ is self adjoint;

(b) if each $T_{n}-T$ is normal;

(c) if and only if the set $\left\{T_{n}^{*}-T^{*}\right\}$ is collectively compact.

Proof. If (a) or (b) holds, then $\left\|\left(T_{n}-T\right)^{2}\right\|=\left\|T_{n}-T\right\|^{2}$ and $\left\|T_{n}-T\right\| \rightarrow 0$ by Proposition 3.3. Alternatively, all three cases follow from Proposition 2.2 and [2, Th. 3.4, 3.5].

4. Convergence of projections. For the main theorem in this section we shall need the following known result, which is usually proved by contradiction. We give a short direct proof. (Note: dimensions may be finite or $\infty$.)

Lemma 4.1. Let $T_{n} \rightarrow T$. Then $\operatorname{dim} T_{n} X \geqq \operatorname{dim} T X$ eventually.

Proof. Let $\left\{T x_{j}: j=1, \cdots, m\right\}$ be linearly independent and define $\mathscr{C}=\left\{\sum_{j=1}^{m} c_{j} x_{j}: \max \left|c_{j}\right|=1\right\}$. Then $\mathscr{C}$ and $T \mathscr{C}$ are compact, so $T_{n} \rightarrow T$ uniformly on $\mathscr{C}$. Since $\min _{x \in \mathscr{E}}\|T x\|>0$, eventually $\min _{x \in \mathscr{C}}\left\|T_{n} x\right\|>0$ and $\left\{T_{n} x_{j}: j=1, \cdots, m\right\}$ is linearly independent. The desired result follows.

Theorem 4.2. Let $E$ and $E_{n}, n \geqq 1$, be projections in $[X]$ such that $E_{n} \rightarrow E$ and $\left\{E_{n}-E\right\}$ is collectively compact. Then, eventually, $\operatorname{dim} E_{n} X=\operatorname{dim} E X$.

Proof. In view of Lemma 4.1, we may assume $\operatorname{dim} E X<\infty$. Then $E$ is compact and, by Proposition $2.1,\left\{E_{n}\right\}$ is collectively compact. 
Suppose that $\operatorname{dim} E_{n} X \geqq m$ for $n \geqq 1$. By the Riesz lemma, there exist linearly independent sets $\left\{x_{n k}: k=1, \cdots, m\right\} \subset E_{n} X, n \geqq 1$, such that

$$
\left\|x_{n k}\right\|=1, \quad\left\|x_{n k}-\sum_{j=1}^{k-1} c_{j} x_{n j}\right\| \geqq 1
$$

for all $n, k$ and $\left\{c_{j}\right\}$. Since $x_{n k}=E_{n} x_{n k} \in\left\{\overline{\left.E_{n}\right\} \mathscr{B}}\right.$, which is compact, there exists a subsequence $\left\{n_{i}\right\}$ and elements $x_{k} \in X$ such that

$$
x_{n_{i} k}=E_{n_{i}} x_{n_{i} k} \rightarrow x_{k} \text { for } k=1, \cdots, m \text {. }
$$

Then

$$
x_{k}\|=1, \quad\| x_{k}-\sum_{n=1}^{k-1} c_{j} x_{j} \| \geqq 1
$$

for all $k$ and $\left\{c_{j}\right\}$, so $\left\{x_{k}: k=1, \cdots, m\right\}$ is linearly independent. Now $E_{n} \rightarrow E$ implies $E_{n_{i}} x_{n_{i} k} \rightarrow E x_{k}$, so that $x_{k}=E x_{k} \in E X$ for all $k$. Thus

$$
\operatorname{dim} E_{n} X \geqq m \text { for all } n \Rightarrow \operatorname{dim} E X \geqq m \text {. }
$$

Apply this result to an arbitrary subsequence of $\left\{E_{n}\right\}$ to conclude that $\operatorname{dim} E_{n} X \leqq \operatorname{dim} E X$ eventually. Lemma 4.1 gives the reverse inequality.

A slight modification of the proof of Theorem 4.2 yields the following result, which will be needed later.

Proposition 4.3. Let $E$ and $E_{n}, n \geqq 1$, be projections in $[X]$ for which $E_{n} \rightarrow E$ and $\left\{E_{n}\right\}$ is collectively compact. Let $Z \subset E X$ and $Z_{n} \subset E_{n} X$ be subspaces such that: $x_{n} \rightarrow x, x_{n} \in Z_{n} \Rightarrow x \in Z$. Then $\operatorname{dim} Z_{n} \leqq \operatorname{dim} Z$ eventually.

5. Resolvent sets, spectra, and resolvent operators. It is convenient to compactify the scalar field with the point $\infty$ if $X$ is complex and the points $\pm \infty$ if $X$ is real. For each $T \in[X]$, let $(\infty-T)^{-1}=0$ in the complex case and $( \pm \infty-T)^{-1}=0$ in the real case. The spectrum, resolvent set, and extended resolvent set of $T$ are denoted by $\sigma(T), \rho(T)$ and $\tilde{\rho}(T)$, respectively.

LEMMA 5.1. For each $T \in[X]$ and each closed set $\Lambda \supset \tilde{\rho}(T)$, the set $\left\{(\lambda-T)^{-1}: \lambda \in \Lambda\right\}$ is compact.

Proof. The set $A$ is compact and the map $\lambda \rightarrow(\lambda-T)^{-1}$ is continuous.

Lemma 5.2. Assume $T_{n} \rightarrow T$ and $\left\{T_{n}-T\right\}$ collectively compact. Then

$$
\left\|\left[\left(T_{n}-T\right)(\lambda-T)^{-1}\right]^{2}\right\| \rightarrow 0 \quad \text { for } \quad \lambda \in \tilde{\rho}(T) .
$$


The convergence is uniform on each closed set $\Lambda \subset \tilde{\rho}(T)$.

Proof. If $\mathscr{K}, \mathscr{M}, \mathscr{N} \subset[X]$, with $\mathscr{K}$ collectively compact, $\mathscr{C}$ bounded, and $\mathscr{N}$ compact, then the sets $\mathscr{K} \mathscr{C}$ and $\mathscr{N} \mathscr{K}$ are collectively compact [2, Prop. 2.3]. Hence, by Lemma 5.1, the set

$$
\left\{(\lambda-T)^{-1}\left(T_{n}-T\right)(\lambda-T)^{-1}: \lambda \in \Lambda, n \geqq 1\right\}
$$

is collectively compact. An application of Proposition 3.1 completes the proof.

Theorem 5.3. Assume $T_{n} \rightarrow T$ and $\left\{T_{n}-T\right\}$ collectively compact. Let $\Omega$ be any neighborhood of $\sigma(T)$ and $\Lambda=\tilde{\rho}(T)-\Omega$. Then:

(a) there exists $N$ such that $\sigma\left(T_{n}\right) \subset \Omega$ and $\Lambda \subset \widetilde{\rho}\left(T_{n}\right)$ for all $n \geqq N$;

(b) the set $\left\{\left(\lambda-T_{n}\right)^{-1}: \lambda \in \Lambda, n \geqq N\right\}$ is bounded;

(c) the functions $\lambda \rightarrow\left(\lambda-T_{n}\right)^{-1}, n \geqq N$, are equicontinuous on $A$;

(d) $\left(\lambda-T_{n}\right)^{-1} \rightarrow(\lambda-T)^{-1}$ uniformly for $\lambda \in \Lambda$. (Estimates corresponding to (b), (c), (d) are given in the proof.)

Proof. For $\lambda \in \rho(T), \lambda-T_{n}=\left[I-\left(T_{n}-T\right)(\lambda-T)^{-1}\right](\lambda-T)$. By Lemma 5.2, there is an $N$ such that

$$
\left\|\left[\left(T_{n}-T\right)(\lambda-T)^{-1}\right]^{2}\right\| \leqq \frac{1}{2}, \quad \lambda \in \Lambda, \quad n \geqq N .
$$

Recall that if $L \in[X]$ and $\left\|L^{2}\right\|<1$ then there exists $(I-L)^{-1} \in[X]$, and

$$
\left\|(I-L)^{-1}\right\| \leqq \frac{\|I+L\|}{1-\left\|L^{2}\right\|} .
$$

Hence, for $\lambda \in \Lambda$ and $n \geqq N$, there exist $\left[I-\left(T_{n}-T\right)(\lambda-T)^{-1}\right]^{-1}$ and $\left(\lambda-T_{n}\right)^{-1}$ in $[X]$,

$$
\left.\left(\lambda-T_{n}\right)^{-1}=(\lambda-T)^{-1}\left[I-\left(T_{n}-T\right)(\lambda-T)^{-1}\right)^{-1}\right],
$$

and

$$
\left\|\left(\lambda-T_{n}\right)^{-1}\right\| \leqq \frac{\left\|(\lambda-T)^{-1}\right\|\left\|I+\left(T_{n}-T\right)(\lambda-T)^{-1}\right\|}{1-\left\|\left[\left(T_{n}-T\right)(\lambda-T)^{-1}\right]^{2}\right\|} .
$$

Since $\left\{T_{n}-T\right\}$ and $\left\{(\lambda-T)^{-1}: \lambda \in \Lambda\right\}$ are necessarily bounded, (a) and (b) follow. Suppose $\left\|\left(\lambda-T_{n}\right)^{-1}\right\| \leqq B$ for $\lambda \in A, n \geqq N$. By the resolvent identity,

$$
\begin{gathered}
\left(\lambda-T_{n}\right)^{-1}-\left(\mu-T_{n}\right)^{-1}=-(\lambda-\mu)\left(\lambda-T_{n}\right)^{-1}\left(\mu-T_{n}\right)^{-1}, \\
\left\|\left(\lambda-T_{n}\right)^{-1}-\left(\mu-T_{n}\right)^{-1}\right\| \leqq B^{2}|\lambda-\mu|
\end{gathered}
$$

for $\lambda, \mu \in \Lambda, n \geqq N$. This implies (c). Note that

$$
\left(\lambda-T_{n}\right)^{-1}-(\lambda-T)^{-1}=\left(\lambda-T_{n}\right)^{-1}\left(T_{n}-T\right)(\lambda-T)^{-1},
$$




$$
\left\|\left(\lambda-T_{n}\right)^{-1} x-(\lambda-T)^{-1} x\right\| \leqq B\left\|\left(T_{n}-T\right)(\lambda-T)^{-1} x\right\|
$$

for $\lambda \in \Lambda, n \geqq N$ and $x \in X$. Therefore, Lemma 5.1 and Proposition 3.2 yield $(\mathrm{d})$.

6. Functions of operators. Henceforth, $X$ is a complex Banach space. The results of this section involve the functional calculus of an operator in $[X]$. To fix notation we review briefly the definitions. A more extended discussion with proofs may be found in [4].

For each $T \in[X]$, let $\mathfrak{F}(T)$ denote the set of locally analytic functions $f$ defined on (not necessarily connected) neighborhoods $\mathscr{D}(f)$ of $\sigma(T)$. For each $f \in \mathfrak{F}(T)$, there is a contour $\Gamma$ in $\mathscr{D}(f) \cap \rho(T)$ which consists of a finite number of rectifiable Jordan curves. Suppose that $\sigma(T)$ lies entirely inside $\Gamma$. Then the operator

$$
f(T)=\frac{1}{2 \pi i} \int_{\Gamma} f(\lambda)(\lambda-T)^{-1} d \lambda
$$

is the limit in the norm topology of the usual approximating sums, and $f(T)$ is independent of the particular choice of $\Gamma$. The map $f(\lambda) \rightarrow f(T)$ is an algebraic homomorphism from $\mathfrak{F}(T)$ into [X].

Theorem 6.1. Assume $T_{n} \rightarrow T$ and $\left\{T_{n}-T\right\}$ collectively compact. Let $f \in \mathfrak{F}(T)$. Then there is an $N$ such that

(a) $f \in \mathfrak{F}\left(T_{n}\right)$ for $n \geqq N$;

(b) $f\left(T_{n}\right) \rightarrow f(T)$;

(c) $\left\{f\left(T_{n}\right)-f(T): n \geqq N\right\}$ is collectively compact.

Proof. Choose $\Gamma \subset \mathscr{D}(f) \cap \rho(T)$ with $\sigma(T)$ inside $\Gamma$. By Theorem 5.3(a) there is an $N$ such that $\sigma\left(T_{n}\right)$ is inside $\Gamma$ for $n \geqq N$. Thus, (a) follows. For $n \geqq N$ and $x \in X$,

$$
f\left(T_{n}\right) x-f(T) x=\frac{1}{2 \pi i} \int_{\Gamma} f(\lambda)\left[\left(\lambda-T_{n}\right)^{-1} x-(\lambda-T)^{-1} x\right] d \lambda .
$$

By Theorem 5.3(d), $f(\lambda)\left[\left(\lambda-T_{n}\right)^{-1} x-(\lambda-T)^{-1} x\right] \rightarrow 0$ uniformly for $\lambda \in \Gamma$ as $n \rightarrow \infty$. This implies (b). For $n \geqq N$,

$$
f\left(T_{n}\right)-f(T)=\frac{1}{2 \pi i} \int_{\Gamma} f(\lambda)(\lambda-T)^{-1}\left(T_{n}-T\right)\left(\lambda-T_{n}\right)^{-1} d \lambda,
$$

where $\left[f(\lambda)(\lambda-T)^{-1}\left(T_{n}-T\right)\left(\lambda-T_{n}\right)^{-1}: \lambda \in \Gamma, n \geqq N\right\}$ is collectively compact by the argument used in the proof of Lemma 5.2. Therefore, by [2, Prop. 2.2], (c) follows.

Without the hypothesis that $\left\{T_{n}-T\right\}$ is collectively compact, $T_{n} \rightarrow T$ would not imply even the existence of $f\left(T_{n}\right)$ for $n$ sufficiently large, much less $f\left(T_{n}\right) \rightarrow f(T)$. 
Essentially the same proof as for Theorem 6.1 yields the following somewhat similar result.

THEOREM 6.2. Assume $T_{n} \rightarrow T$ and $\left\{T_{n}-T\right\}$ collectively compact. Let $f_{n}, f \varepsilon \mathfrak{F}(T)$ with $\mathscr{D}\left(f_{n}\right) \supseteqq \mathscr{D}(f)$. If $f_{n}$ converges to $f$ uniformly on $\mathscr{D}(f)$, then $f_{n}\left(T_{n}\right)$ is eventually defined and $f_{n}\left(T_{n}\right) \rightarrow f(T)$.

Complementary spectral sets $\sigma_{1}$ and $\sigma_{2}$ associated with an operator $T$ are disjoint, relatively closed subsets of $\sigma(T)$ with $\sigma(T)=\sigma_{1} \cup \sigma_{2}$ (either $\sigma_{1}$ or $\sigma_{2}$ may be void). Given $\sigma_{1}$ and $\sigma_{2}$, there is a contour $\Gamma$ in $\rho(T)$ with $\sigma_{1}$ inside $\Gamma$ and $\sigma_{2}$ outside $\Gamma$. Conversely, every contour $\Gamma$ in $\rho(T)$ separates $\sigma(T)$ into complementary spectral sets $\sigma_{1}$ and $\sigma_{2}$. With this notation, the operator.

$$
E_{\Gamma}(T)=\frac{1}{2 \pi i} \int_{\Gamma}(\lambda-T)^{-1} d \lambda
$$

is the spectral projection and $E_{\Gamma}(T) X$ the spectral subspace corresponding to $\sigma_{1}$. Theorems 6.1 and 4.2 yield

Proposition 6.3. Assume $T_{n} \rightarrow T$ and $\left\{T_{n}-T\right\}$ collectively compact. Let $\Gamma$ be a contour in $\rho(T)$. Then there is an $N$ such that for $n \geqq N: E_{\Gamma}\left(T_{n}\right)$ is defined, $E_{\Gamma}\left(T_{n}\right) \rightarrow E_{\Gamma}(T),\left\{E_{\Gamma}\left(T_{n}\right)-E_{\Gamma}(T)\right\}$ is collectively compact, and $\operatorname{dim} E_{\Gamma}\left(T_{n}\right) X=\operatorname{dim} E_{\Gamma}(T) X$.

7. Eigenvalues and eigenvectors. Throughout this final section assume $T_{n} \rightarrow T$ and $\left\{T_{n}-T\right\}$ collectively compact. The null space of an operator $L$ will be denoted by $\mathscr{N}(L)$.

Let $\mu$ be an isolated eigenvalue of $T$ with finite index (ascent and descent) $\nu$ and

$$
P(\lambda)=(\mu-\lambda)^{\nu}
$$

Let $\Gamma$ be any contour in $\rho(T)$ with $\mu$ the only point of $\sigma(T)$ inside $\Gamma$, and $E=E_{\Gamma}(T)$. Then

$$
\begin{aligned}
E X & =\mathscr{N}[P(T)], \\
E P(T) & =P(E T)=0,
\end{aligned}
$$

and $P$ divides every polynomial $Q$ such that $Q(E T)=0$. Thus, $P$ is the minimal polynomial for $E T$. Assume $\operatorname{dim} E X<\infty$. Then $E$ is compact.

By Propositions 2.1 and 6.3 there is an $N$ such that for $n \geqq N$ : $E_{n}=E_{\Gamma}\left(T_{n}\right)$ is defined, $E_{n} \rightarrow E,\left\{E_{n}\right\}$ is collectively compact, and $\operatorname{dim} E_{n} X=\operatorname{dim} E X$. Assume $n \geqq N$ henceforth. Since $\operatorname{dim} E_{n} X<\infty$, the part of $\sigma\left(T_{n}\right)$ inside $\Gamma$ consists of a finite set of eigenvalues $\mu_{n k}$ 
with finite indices $\nu_{n k}, k=1, \cdots, k_{n}$. Then Theorem 5.3(a) implies

Proposition 7.1. $\max _{k=1, \cdots, k_{n}}\left|\mu_{n k}-\mu\right| \rightarrow 0$ as $n \rightarrow \infty$.

Let

$$
P_{n}(\lambda)=\prod_{k=1}^{k_{n}}\left(\mu_{n k}-\lambda\right)^{\nu} n k
$$

Then

$$
\begin{gathered}
E_{n} X=\mathscr{V}\left[P_{n}\left(T_{n}\right)\right], \\
E_{n} P_{n}\left(T_{n}\right)=P_{n}\left(E_{n} T_{n}\right)=0,
\end{gathered}
$$

and $P_{n}$ is the minimal polynomial for $E_{n} T_{n}$. Let $\nu_{n}$ be the degree of $P_{n}$. Then

$$
\nu_{n}=\sum_{k=1}^{k_{n}} \nu_{n k}
$$

THEOREM 7.2. $\nu_{n} \geqq \nu$ for $n$ sufficiently largs.

Proof. Suppose $\nu_{n_{i}}=\beta$ for some subsequence. By Theorem 6.1 $E_{n} T_{n} \rightarrow E T$ and $\left\{E_{n} T_{n}-E T\right\}$ is collectively compact. Hence

$$
O=P_{n_{i}}\left(E_{n_{i}} T_{n_{i}}\right) \rightarrow(\mu-E T)^{3}
$$

by Proposition 7.1 and Theorem 6.2. Therefore $\beta \geqq \nu$ and the conclusion follows.

The next theorem relates generalized eigenmanifolds of $T_{n}$ and $T$. Let $\gamma$ be any integer such that $0 \leqq \gamma \leqq \nu$. By Theorem 7.2, for $n$ sufficiently large there exist integers $\gamma_{n k}$ such that

$$
0 \leqq \gamma_{n k} \leqq \nu_{n k}, \quad \sum_{k=1}^{k_{n}} \gamma_{n k}=\gamma \text {. }
$$

Let

$$
\begin{array}{cc}
Q(T)=(\mu-T)^{\nu}, & Q_{n}\left(T_{n}\right)=\prod_{k=1}^{k_{n}}\left(\mu_{n k}-T_{n}\right)^{\nu_{n k}}, \\
Z=\mathscr{N}[Q(T)], \quad Z_{n}=\mathscr{N}\left[Q_{n}\left(T_{n}\right)\right] .
\end{array}
$$

THEOREM 7.3. For $n$ sufficiently large and every choice of the $\boldsymbol{\nu}_{n k}, \operatorname{dim} Z_{n} \leqq \operatorname{dim} Z$.

Proof. From $T_{n} \rightarrow T$ and Proposition 7.1, $Q_{n}\left(T_{n}\right) \rightarrow Q(T)$. Hence, $x_{n} \rightarrow x, x_{n} \in Z_{n} \Rightarrow x \in Z$. By Theorem $4.3, \operatorname{dim} Z_{n} \leqq \operatorname{dim} Z$ eventually.

The final result relates eigenmanifolds of $T_{n}$ and $T$.

Corollary 7.4. For $n$ sufficiently large,

$$
\operatorname{dim} \mathscr{N}\left(\mu_{n k}-T_{n}\right) \leqq \operatorname{dim} \mathscr{N}(\mu-T), \quad k=1, \cdots, k_{n} .
$$




\section{REFERENCES}

1. P.M. Anselone and R.H. Moore, Approximate solutions of integral and operator equations, J. Math. Anal. Appl. 9 (1964), 268-277.

2. P.M. Anselone and T.W. Palmer, Collectively compact sets of linear operators, Pacific J. Math. 25 (1968), 423-431.

3. K. E. Atkinson, The numerical solution of the eigenvalue problem for compact integral operators, Trans. Amer. Math. Soc. 129 (1967), 458-465.

4. N. Dunford and J. T. Schwartz, Linear Operators, Part I, Interscience, 1958.

Received February, 27, 1967. Sponsored by the Mathematics Research Center, United States Army, Madison, Wisconsin, under Contract No.: DA-31-124-ARO-D-462.

Oregon State University, Corvallis

UNIVERSITY OF KANSAS, LAWRENCE 



\title{
PACIFIC JOURNAL OF MATHEMATICS
}

\author{
EDITORS
}

\section{H. ROYDEN}

Stanford University

Stanford, California

\author{
J. P. JANS \\ University of Washington \\ Seattle, Washington 98105
}

\section{J. DugundJI}

Department of Mathematics

University of Southern California

Los Angeles, California 90007

\section{RICHARD ARENS}

University of California

Los Angeles, California 90024

\section{ASSOCIATE EDITORS}
E. F. BECKENBACH
B. H. NEUMANN
F. WOLF
K. YOSIDA

\section{SUPPORTING INSTITUTIONS}

\author{
UNIVERSITY OF BRITISH COLUMBIA \\ CALIFORNIA INSTITUTE OF TECHNOLOGY \\ UNIVERSITY OF CALIFORNIA \\ MONTANA STATE UNIVERSITY \\ UNIVERSITY OF NEVADA \\ NEW MEXICO STATE UNIVERSITY \\ OREGON STATE UNIVERSITY \\ UNIVERSITY OF OREGON \\ OSAKA UNIVERSITY \\ UNIVERSITY OF SOUTHERN CALIFORNIA
}

\author{
STANFORD UNIVERSITY \\ UNIVERSITY OF TOKYO \\ UNIVERSITY OF UTAH \\ WASHINGTON STATE UNIVERSITY \\ UNIVERSITY OF WASHINGTON \\ AMERICAN MATHEMATICAL SOCIETY \\ CHEVRON RESEARCH CORPORATION \\ TRW SYSTEMS \\ NAVAL WEAPONS CENTER
}

Mathematical papers intended for publication in the Pacific Journal of Mathematics should be in typed form or offset-reproduced, double spaced with large margins. Underline Greek letters in red, German in green, and script in blue. The first paragraph or two must be capable of being used separately as a synopsis of the entire paper. It should not contain references to the bibliography. Manuscripts, in duplicate if possible, may be sent to any one of the four editors. All other communications to the editors should be addressed to the managing editor, Richard Arens, University of California, Los Angeles, California 90024.

Each author of each article receives 50 reprints free of charge; additional copies may be obtained at cost in multiples of 50 .

The Pacific Journal of Mathematics is published monthly. Effective with Volume 16 the price per volume (3 numbers) is $\$ 8.00$; single issues, $\$ 3.00$. Special price for current issues to individual faculty members of supporting institutions and to individual members of the American Mathematical Society: $\$ 4.00$ per volume; single issues $\$ 1.50$. Back numbers are available.

Subscriptions, orders for back numbers, and changes of address should be sent to Pacific Journal of Mathematics, 103 Highland Boulevard, Berkeley 8, California.

Printed at Kokusai Bunken Insatsusha (International Academic Printing Co., Ltd.), 7-17, Fujimi 2-chome, Chiyoda-ku, Tokyo, Japan.

PUBLISHED BY PACIFIC JOURNAL OF MATHEMATICS, A NON-PROFIT CORPORATION

The Supporting Institutions listed above contribute to the cost of publication of this Journal, but they are not owners of publishers and have no responsibility for its content or policies. 


\section{Pacific Journal of Mathematics}

\section{Vol. 25, No. $3 \quad$ November, 1968}

Philip Marshall Anselone and Theodore Windle Palmer, Collectively

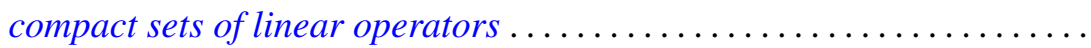

Philip Marshall Anselone and Theodore Windle Palmer, Spectral analysis of collectively compact, strongly convergent operator sequences.........

Edward A. Bender, Characteristic polynomials of symmetric matrices...... 433

Robert Morgan Brooks, The structure space of a commutative locally convex

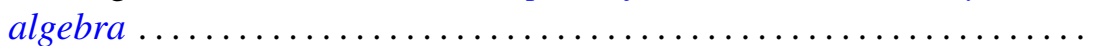

Jacob Feldman and Frederick Paul Greenleaf, Existence of Borel

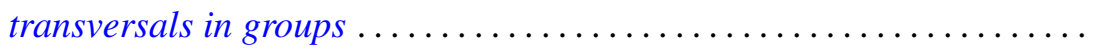

Thomas Muirhead Flett, Mean values of power series 463

Richard Vernon Fuller, Relations among continuous and various

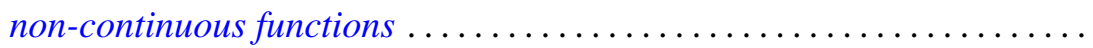

Philip Hartman, Convex sets and the bounded slope condition ............

Marcel Herzog, On finite groups containing a CCT-subgroup with a cyclic Sylow subgroup .

James Secord Howland, On the essential spectrum of Schroedinger

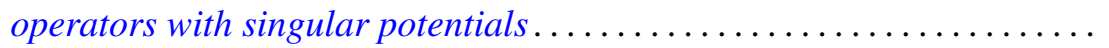

Thomas William Hungerford, On the structure of principal ideal rings .....

Paul Joseph Kelly and Ernst Gabor Straus, Curvature in Hilbert geometries. II mpati Madhusudana Rao, Linear functionals on Orlicz spaces:

Malempati Madhusudana Rao, Linear functionals on Orli
$\quad$ General theory............................
Stanley F. Robinson, Theorems on Brewer sums.......
Ralph Tyrrell Rockafellar, A general correspondence betw

Malempati Madhusudana Rao, Linear functiona
$\quad$ General theory.........................
Stanley F. Robinson, Theorems on Brewer sums
Ralph Tyrrell Rockafellar, A general corresponden

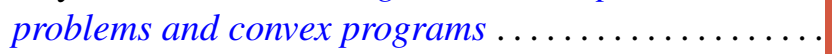

Richard Benjamin Sher, Defining subsets of $E^{3}$ by cubes.

Howard Jacob Weiner, Invariant measures and Cesàro summability... 